\title{
Pathogenicity of commercial entomopathogenic fungal strains on the avocado seed borer (ASB), Heilipus lauri (Coleoptera: Curculionidae) under laboratory conditions
}

\author{
Andrea P. Clavijo ${ }^{1}$. Claudia M. Holguin ${ }^{1}$ (I) \\ Received: 10 December 2019 / Accepted: 18 May 2020 / Published online: 30 May 2020 \\ (C) The Author(s) 2020
}

\begin{abstract}
The avocado seed borer, (ASB) Heilipus lauri Boheman 1845 (Coleoptera: Curculionidae) is an official quarantine pest limiting avocado production and fruit exports from Colombia to pest-free countries. To provide alternatives to manage ASB, the objective of this study was to determine the potential use of commercial strains of Beauveria bassiana and Metarhizium anisopliae as biological control agents of this pest. Pathogenicity of the strains was evaluated by complete immersion of the insect in a spore solution (direct inoculation) or by insect contact with inoculated fruit (indirect inoculation). The $B$. bassiana strain caused higher mortality $(\mathrm{DF}=3, \mathrm{~F}=25.7, P=0.0002)$, showing an almost eight-fold increase, $55 \%$ and $79 \%$ mortality, for both concentrations used, $2.5 \times 10^{8}$ spores $/ \mathrm{mL}$ or $2.5 \times 10^{9}$ spores $/ \mathrm{mL}$, respectively. Additionally, the B. bassiana strain showed shorter median survivorship using direct inoculation (15.8 to 8.7 days), a longer delay in the feeding initiation time $(50 \mathrm{~h})$, and a decrease in the fruit intake (Anti-feeding index above 50) after indirect inoculation. To our knowledge, this is the first report about the pathogenicity of a commercial B. bassiana strain against ASB in Colombia.
\end{abstract}

Keywords Avocado seed weevil $\cdot$ Biological control $\cdot$ Beauveria bassiana $\cdot$ Mortality $\cdot$ Sublethal effects

\section{Introduction}

The rapid increase of worldwide demand (FAOSTAT 2016) for avocado (Persea americana Mill) has positioned this crop in an important place in Colombian economy (AGRONET 2016). Currently, most of the Colombian avocado exports are directed towards European Union countries, but new targets have been reached to expand its commerce, such as the United States and Japan.

One of the main insect pests that restricts exportation and has been recognized as a threat to avocado production in the U.S is the avocado weevil or avocado seed borer (ASB) Heilipus lauri Boheman, 1845 (Coleoptera: Curculionidae) (Hoddle 2011). This pest was initially reported in Mexico

Claudia M. Holguin

cholguin@agrosavia.co

1 Corporación Colombiana de Investigación Agropecuaria, Agrosavia. Centro de Investigación La Selva, Rionegro, Antioquia, Colombia
(McKenzie 1935) and since then has been found in Colombia, Costa Rica, Guatemala, Nicaragua, El Salvador, among others (Wolfenberger and Colburn 1966; EPPO 1970). In Colombia, ASB has been reported in the main regions of avocado production and has been found in a wide altitudinal range across the country (Corpoica 2013), which has led it to be classified as an official control pest and resulted in more rigorous control measurements to avoid its spread. Survival of this insect depends on the availability of avocado fruits (Diaz et al. 2017) and it has shown a preference for the Hass cultivar (Medina-Quiroz et al. 2010), the primary variety exported from Colombia. Heilipus lauri presence in a grove can cause a significant loss of production due to the damage caused by the larvae feeding on fruit pulp and seed, which often leads to premature fruit drop (Pena 1998). In Colombia, losses from ASB damage can reach up to $60 \%$ (Caicedo et al. 2010; Medina-Quiroz et al. 2010).

Current control measurements for this pest are focused mainly on a combination of cultural practices and insecticide applications (SENASICA-DGSV 2016; Hernandez et al. 2017). However, most of the registered insecticides 
for avocado in Colombia belong to toxicity level 2, exposing farmers and pollinators to highly toxic chemicals as well as increasing the risk of toxic residuals on exported fruit (Sanchez-Bayo and Goka 2014). The use of biological agents not only provides a solution to these issues, but it could be also used as an ecologically sustainable alternative (Lacey and Shapiro-ilan 2008; Ambethgar 2009) and has been recognized as a suitable alternative for other avocado pests (Hoddle 2011).

Entomopathogenic microorganisms are recognized for their low toxicity to non-target organisms, minimal residuals, and their potential to reduce the use of conventional pesticides (Strasser et al. 2000; Gilbert and Gill 2010; Abrol and Shankar 2012). It is possible to find fungi, bacteria, nematodes and viruses, in different formulations, as microbiological control agents for a wide range of insect pests (Lacey and Shapiro-ilan 2008; Abrol and Shankar 2012). A common approach during the development of new formulations based on entomopathogenic microorganisms consists of the isolation of native strains from the target pest (Bruck 2004; Barra et al. 2013; Gouli et al. 2013), which increases the specificity of the entomopathogen and reduces the problem of persistence, as driven by environmental and ecological factors (Gilbert and Gill 2010). However, the process from isolation and identification to the formulation and evaluation of the product can take several years.

In Colombia, around 60 biological insecticides (including strains of Beauveria bassiana, B. brogniartii, Metarhizium anisopliae, Paecilomyces lilacinus, $P$. fumosoroseus, Lecanicillium lecanii, Saccharomyces cerevisiae, Bacillus thuringiensis var Kurstaki, and Paenibacillus popillia) were registered in 2018 for different target insect pests (ICA 2019), but none of them have been tested against ASB in avocado crops. Despite limitations in the commercialization of entomopathogens for ASB control in Colombia, as well as a lack of information on their efficiency, the application of Beauveria bassiana and Metarhizium anisopliae has been recommended and used as part of an integrated pest management program for ASB (Corpoica 2013; Williams et al. 2013; SENASICA-DGSV 2016).

The use of native entomopathogens for ASB would be a desirable approach for its control, but the restrictions to export the fruit to foreign countries (Pena 1998; USDA 2014) and damage losses (AGRONET 2016) due to this pest require a rapid acting and sustainable strategy. Thus, the aim of this study was to evaluate the potential use of Beauveria bassiana and Metharizhium anisopliae commercial formulations to control ASB. We tested the pathogenicity of these strains against ASB adults and determined the effect of B. bassiana on beetle survivorship and feeding under laboratory conditions.

\section{Materials and methods}

\section{Insects}

Rearing was established according to Diaz et al. (2017) in the laboratory $\left(20,7 \pm 2{ }^{\circ}\right.$ C, R.H $69 \pm 6 \%$ and $8: 12$ (L: D)), at the La Selva research center of the Corporación Colombiana de Investigación Agropecuaria (AGROSAVIA), Rionegro, Antioquia, Colombia ( $6^{\circ} 07^{\prime} 46.4^{\prime \prime}$ LN, $75^{\circ} 24^{\prime} 51,8^{\prime \prime}$ LW at 2120 masl). Briefly, adult beetles were collected from infested avocado (cv. Hass) fields, located in El Retiro $\left(6^{\circ} 01^{\prime}\right.$ $40^{\prime \prime} \mathrm{LN}, 75^{\circ} 27^{\prime} 19^{\prime \prime} \mathrm{LW}$ at 2484 masl), Antioquia, Colombia. Individuals were placed in perforated plastic containers $(40 \mathrm{~cm} \times 30 \mathrm{~cm} \times 31 \mathrm{~cm})$, covered with a mesh to allow aeration, and fed with avocado c.v Hass fruits every two days. Eggs were individualized in small ( $4 \mathrm{~cm}$ diameter) sterile containers with a wet paper towel, and newly emerged larvae were placed inside avocado seeds until adult emergence (Diaz et al. 2017). For all bioassays, two months old ASB adults were used to ensure that only young, healthy and active individuals of the same age were included in the experiments.

\section{Entomopathogenic fungi}

Two commercial wettable powder formulations of B. bassiana (B.b-1) and M. anisopliae (M.a-1) were tested in this study. Following the manufacturers recommendations, both strains were reactivated on ASB adults before formulation. Prior to the experiments, a viability test was performed by spreading $0.1 \mathrm{~mL}$ of a dilution of the spore solutions over acidic-PDA (lactic acid $0.05 \%$ ) and incubated for 7 days at $25{ }^{\circ} \mathrm{C}$.

\section{Pathogenicity bioassay for commercial entomopathogenic fungi formulations against ASB adults}

The recommended commercial concentration (CC) $\left(2.5 \times 10^{8}\right.$ spores $/ \mathrm{mL}$ for each product) and ten times $\mathrm{CC}(\mathrm{C} 10)$ were used for each commercial formulation. The spore solutions were prepared by diluting $25 \mathrm{~g}$ of dry powder in $1 \mathrm{~L}$ of sterile distilled water and incubated at room temperature for $1 \mathrm{~h}$ to ensure homogeneity, according to manufacturer instructions. The solution was filtered through a sterile cheese cloth and spore counts were confirmed by depositing an aliquot on a hemocytometer and viewing under a microscope.

For inoculation, the coadyuvant Carrier $0.012 \%$ (Colinagro, Bogotá, Colombia) was added to the solution. Direct inoculation was carried out by placing the insect in a mesh pocket $(5 \times 5 \mathrm{~cm})$ and completely immerse it for one minute in $100 \mathrm{~mL}$ of this spore solution contained in a $500 \mathrm{~mL}$ beaker. Afterwards, insects were placed individually 
in plastic containers $(15 \mathrm{~cm} \times 10 \mathrm{~cm} \times 10 \mathrm{~cm})$ with an uninoculated avocado fruit. For indirect inoculation, avocado fruits were immersed for $1 \mathrm{~min}$ in the spore solution and placed in the plastic container with an uninoculated insect. All containers were capped with plastic lids punctured for ventilation. As negative control, a solution of coadyuvant $0.012 \%$ and sterile distilled water was used. Three groups of 10 individuals were used for each concentration, for a total of 30 individuals per concentration for each inoculation method. To ascertain death by the entomopathogenic fungi, dead insects were placed in humid chambers that consisted of petri dishes bottom-lined with sterile filter paper and wetted with sterile distilled water. Humid chambers were incubated at $25{ }^{\circ} \mathrm{C}$ for 10 days and fungi were identified using morphological characteristics. Mortality and days to death were recorded for 31 days for both assays. Estimation of mortality for each spore concentration was calculated using the Abbot correction (Abbott 1925). Mortality values were compared using ANOVA in SAS software, version 9.4, 2012 for Windows. When mortalities did not follow normal distribution assumptions, values were $\log _{10}$ transformed prior to ANOVA and means differences were separated using Tukey's HSD test at a significance level 0.05 .

\section{Pathogenicity of $B$. bassiana at different concentrations against ASB adults}

Following the pathogenicity bioassay, subsequent evaluations were performed using only the Bb-1 strain. Inoculation was carried out by direct and indirect methods as described above. After inoculation, insects were placed in the plastic containers and capped with plastic lids punctured for ventilation. For negative control, the inoculations were carried out in a similar solution without the entomopathogens.

For this assay, five spore concentrations were evaluated: CC $\left(2.5 \times 10^{8}\right.$ spores $\left./ \mathrm{mL}\right), \mathrm{C} 2.5\left(6.25 \times 10^{8}\right.$ spores $\left./ \mathrm{mL}\right), \mathrm{C} 5$ $\left(1.25 \times 10^{9}\right.$ spores $\left./ \mathrm{mL}\right), \mathrm{C} 7.5\left(1.87 \times 10^{9}\right.$ spores $\left./ \mathrm{mL}\right)$ and C10 $\left(2.5 \times 10^{9}\right.$ spores $\left./ \mathrm{mL}\right)$. Viability of all spore concentrations was confirmed by observing colony forming units after spreading $0.1 \mathrm{~mL}$ of a dilution of the spore solutions over acidic-PDA (lactic acid $0.05 \%$ ) and incubation for 7 days at $25{ }^{\circ} \mathrm{C}$. Thirty ASB individuals were divided into three groups of 10 individuals for each spore concentration and each inoculation method. Mortality and days to death were recorded for 31 days for both assays. Estimation of mortality for each spore concentration was calculated using the Abbot correction (Abbott 1925). Mortalities for indirect inoculation followed normal distribution assumptions and were compared using ANOVA, and means differences were separated using Tukey's HSD test at a significance level 0.05. The mortality results were used to calculate the median lethal concentration $\left(\mathrm{LC}_{50}\right)$ for direct and indirect inoculation methods using the PROBIT procedure on SAS software, version 9.4, 2012 for Windows. In addition, the median survivorship time $\left(\mathrm{MST}_{50}\right)$ was calculated using the Kaplan-Meier analysis (Kaplan and Meier 1958) through PROC LIFETEST on the SAS software, version 9.4, 2012 for Windows, which also compares survival curves. In this comparison the Log-rank test and Wilcoxon test were used to determine differences in the survival curves among concentrations within each inoculation method, and an adjustment for multiple comparisons were carried out for each test using the Bonferroni correction (SAS-Institute-Inc 2004) .

\section{Effects of a commercial strain of $B$. bassiana on ASB adults feeding}

Three spore concentrations (C2.5: $6.25 \times 10^{8}$ spores $/ \mathrm{mL}$, C7.5: $1.88 \times 10^{9}$ spores $/ \mathrm{mL}$ and C10: $2.5 \times 10^{9}$ spores $/ \mathrm{mL}$ ) were used to determine B. bassiana effects on ASB feeding. Inoculations were conducted using the same procedures as described above.

Before the inoculations, two squares of $3 \mathrm{~cm} \times 3 \mathrm{~cm}$ were randomly marked on each avocado fruit. To estimate the consumed area on the fruit surface, the number of perforations made by ASB adults during feeding within these two areas and their diameter were measured using a digital caliper. The consumed area was used to calculate the Anti-Feeding Index (AFI) (Singh and Pant 1980):

$A F I=\frac{C-T}{C+T} \times 100$

Where $\mathrm{C}$ represents the average area consumed by the control, and $\mathrm{T}$ the average area consumed during treatments. Higher AFI values indicate lower food consumption.

Furthermore, the feeding initiation time (FIT) was recorded as the time point in which the first perforation occurred on the fruit surface, regardless if it was in or out of the drawn squares. Three groups of 10 individuals were used for this assay, for a total of 30 insects per spore concentration. All feeding parameters were analyzed in separate sets by inoculation method and in some cases, did not follow normal distribution assumptions; thus, FIT for both inoculation methods and AFI for indirect inoculation were analyzed using the Kruskal Wallis test through PROC NPARWAY in SAS software, version 9.4, 2012 for Windows, and pairwise two-sided multiple comparison analysis was carried out through the Dwass, Steel, Critchlow-Fligner method to determine differences between concentrations. The remaining set of data, AFI for direct inoculation, was analyzed by ANOVA and means differences were calculated using Tukey's HSD test at a significance level of 0.05 using the SAS software, version 9.4, 2012 for Windows. 


\section{Results}

\section{Pathogenicity bioassay for commercial entomopathogenic formulations against ASB adults}

In this assay adult beetles inoculated with $B$. bassiana showed mortalities of $55.7 \%( \pm 9.12)$ and $79.31 \%( \pm 5.97)$ for $C C$ and $\mathrm{C} 10$, respectively. In the case of $M$. anisopliae, the mortalities were significantly lower than with $B$. bassiana $(\mathrm{DF}=3, \mathrm{~F}=$ $25.7, P=0.0002)$ at $6.89 \%( \pm 5.97)$ and $10.34 \%( \pm 3.44)$, for $\mathrm{CC}$ and $\mathrm{C} 10$ respectively. In addition, the use of a higher concentration of $B$. bassiana caused a higher mortality, providing evidence for a dose-response effect on the pathogenicity of the strain. These results confirmed the potential of B.b-1 to control adults of $H$. lauri and were the foundations for subsequent assays with this strain.

\section{Pathogenicity of $B$. bassiana at different concentrations against ASB adults}

The direct inoculation of ASB with B.b-1 at any of the tested concentrations caused higher mortalities in comparison to the indirect inoculation (Table 1). For the direct inoculation method, all tested concentrations except CC caused mortalities of $100 \%$ with no significant differences among concentrations (DF $=4, \mathrm{~F}=4.0, P=0.0543$ ) (Table 1). The median survival time $\left(\mathrm{MST}_{50}\right)$ for direct inoculation decreased for all concentrations compared with the control, resulting in a decrease of at least two weeks (Table 2) and confirming the effect of concentration of B. bassiana on ASB survival. Analysis of the survival curves generated for direct inoculation resulted in significant differences among them (Log-rank $\alpha=0.05$, $\chi^{2}=142.2, P<0.0001$. Wilcoxon $\alpha=0.05, \chi^{2}=106.6$,

Table 1 Mortality of ASB adults after direct and indirect inoculation with five different concentrations of a commercial strain of $B$. bassiana (B.b-1)

\begin{tabular}{lll}
\hline Conc & \multicolumn{2}{c}{ Mortality $^{*} \pm \mathrm{SE}$} \\
\cline { 2 - 3 } & Direct inoculation (Insect) & Indirect inoculation (Fruit) \\
\hline Control & 0 & $10 \pm 5.7$ \\
CC & $93.1 \pm 3.4$ & $30 \pm 5.7$ \\
C2.5 & $100 \pm 0.0$ & $30 \pm 5.7$ \\
C5 & $100 \pm 0.0$ & $30 \pm 11.5$ \\
C7.5 & $100 \pm 0.0$ & $40 \pm 10$ \\
C10 & $100 \pm 0.0$ & $50 \pm 5.7$ \\
\hline
\end{tabular}

* Abbot corrected formula. CC: commercial concentration $\left(2.5 \times 10^{8}\right.$ spores $/ \mathrm{mL}), \mathrm{C} 2.5\left(6.25 \times 10^{8}\right.$ spores $\left./ \mathrm{mL}\right), \mathrm{C} 5\left(1.25 \times 10^{9}\right.$ spores $\left./ \mathrm{mL}\right)$, C7.5 $\left(1.87 \times 10^{9}\right.$ spores $\left./ \mathrm{mL}\right)$ and C10 $\left(2.5 \times 10^{9}\right.$ spores $\left./ \mathrm{mL}\right)$. Direct inoculation was carried out by immersion of insects in a spore solution. Indirect inoculation refers to immersion of fruits used afterwards for ASB adults feeding
$P<0.0001$ ) (Fig. 1). Paired comparisons showed that control individuals had a higher probability of survival compared to insects inoculated with any concentration of B. bassiana, and significantly lower survival for C10 compared to C5 (LogRank test and Wilcoxon test $\alpha=0.05, P<0.05$ ).

In the case of indirect inoculation, the mortality of ASB adults increased proportionally to the spore concentration, but no significant differences were found among concentrations $(\mathrm{F}=3.2059, \mathrm{DF}=4 P=0.0615)$ (Table 1). For the $\mathrm{MST}_{50}$, a reduction was observed for all the concentrations, decreasing the survival of ASB by up to 5 days with the C7.5 and $\mathrm{C} 10$ concentrations of $B$. bassiana (Table 2). The analysis demonstrated differences among the survival of indirect inoculation were significant (Log-rank $\alpha=0.05, \chi^{2}=24.4, P=$ 0.0002 . Wilcoxon $\left.\alpha=0.05, \chi^{2}=23.5, P=0.0003\right)$, and the paired comparison showed a significantly lower probability of survival for individuals inoculated with $\mathrm{C} 10$ and $\mathrm{C} 7.5 \mathrm{com}$ pared to the control, as well as a lower survival for $\mathrm{C} 10$ with CC. For both inoculation methods, more than $98 \%$ of the dead insects showed typical B. bassiana sporulation identified by microscopy, indicating evidence on the performance of this strain on ASB adult insects (Fig. 2).

Additionally, the mortality of ASB adults inoculated directly with B.b-1 using different concentrations was used to calculate the median lethal concentration $\left(\mathrm{MLC}_{50}\right)$. The $\mathrm{MLC}_{50}$ estimated for direct inoculation was lower in comparison to the indirect inoculation, indicating that a higher amount of B.b-1 is required to kill the insect when applied on surfaces (Table 3).

\section{Feeding effects on ASB adults inoculated with B. bassiana}

Inoculation with B.b-1 of the avocado fruit used for feeding ASB adults (indirect) caused an increase of at least $40 \mathrm{~h}$ in the FIT time point where the first feeding perforation occurred in the avocado fruit, and all concentrations tested caused significantly higher (Kruskal Wallis, $\chi^{2}=54.9, \mathrm{DF}=3, P<0.0001$ ) FIT in comparison with the control (Fig. 3b). In contrast, for direct inoculation the significant difference (Kruskal Wallis, $\left.\chi^{2}=23.4, \mathrm{DF}=3, P<0.0001\right)$ in FIT was obtained with the concentration $\mathrm{C} 10$, although the increase in FIT was proportional to the concentration of spores (Fig. 3a). Additionally, no significant differences were found for control mortalities between inoculation methods (Wilcoxon $Z=-0.6174$, $P=0.9987$ ), indicating that the immersion of insect or fruit (direct and indirect inoculations, respectively) did not interfere with the feeding pattern.

For indirect inoculation, higher AFI values were found in comparison with the insect immersion method (Fig. 3c, d), suggesting lower food ingestion. All AFI values for the three concentrations using the indirect inoculation method were significantly higher (Kruskal Wallis, $\chi^{2}=31.66, D F=3$, 
Table 2 Median survival time $\left(\mathrm{MST}_{50}\right)$ of ASB adults after direct and indirect inoculation with five different concentrations of a commercial strain of B. bassiana (B.b-1)

\begin{tabular}{|c|c|c|c|c|}
\hline \multirow[t]{3}{*}{ Conc } & \multicolumn{4}{|c|}{ Median Survival Time - MST $_{50}$} \\
\hline & \multicolumn{2}{|c|}{ Direct inoculation (Insect) } & \multicolumn{2}{|c|}{ Indirect inoculation (Fruit) } \\
\hline & $\mathrm{ST}_{50}{ }^{+}$Days $\pm \mathrm{SE}$ & $95 \%$ Conf. limit ${ }^{a}$ & $\mathrm{ST}_{50}{ }^{+}$Days $\pm \mathrm{SE}$ & $95 \%$ Conf. limit $^{\mathrm{a}}$ \\
\hline Control & $32 \pm 0.0$ & - & $32 \pm 0.0$ & - \\
\hline $\mathrm{CC}$ & $15.83 \pm 1.16$ & $12-18$ & $30.2 \pm 1.13$ & - \\
\hline $\mathrm{C} 2.5$ & $11.03 \pm 0.54$ & $11-12$ & $29.66 \pm 0.84$ & - \\
\hline $\mathrm{C} 5$ & $13.64 \pm 0.87$ & $11-18$ & $28.85 \pm 1.22$ & - \\
\hline C7.5 & $10.56 \pm 0.59$ & $7-13$ & $27.33 \pm 1.27$ & $26-32$ \\
\hline $\mathrm{C} 10$ & $8.76 \pm 0.46$ & $7-11$ & $27.20 \pm 1.32$ & $26-32$ \\
\hline
\end{tabular}

CC: commercial concentration $\left(2.5 \times 10^{8}\right.$ spores $\left./ \mathrm{mL}\right)$. C2.5, C5, C7.5 and C10 correspond to 2.5, 5, 7.5 and 10fold times CC, respectively. Direct inoculation was carried out by immersion of insects in a spore solution. For indirect inoculation avocado fruits were immersed in a spore solution. ${ }^{+} \mathrm{ST}_{50}$ calculated by Kaplan-Meier analysis. ${ }^{\text {a }}$ 95\% Confidence limits for 50 percentiles
$P<0.0001)$ compared with the control (Fig. 3d) (AFI $>50$ for all three concentrations), while the direct method only produced significant $(\mathrm{DF}=3, \mathrm{~F}=4.8, P=0.0035)$ AFI values with the concentration $\mathrm{C} 7.5$ and $\mathrm{C} 10$, resulting in $\mathrm{AFI}$ values around 30 for both concentrations.

\section{Discussion}

The pathogenicity of commercial formulations of $B$. bassiana and $M$. anisopliae was evaluated against ASB adults, an official control pest of avocado crops in Colombia, which showed susceptibility to both strains, although significant effects were observed only with the $B$. bassiana strain.

The use of entomopathogens, such as B. bassiana, in integrated management programs for insect pest control has been recognized for several years (Lacey and Goettel 1995). However, there are few reports of their use against ASB. In Mexico and Colombia, the use of biological control (including
B. bassiana and M. anisopliae) has been proposed for ASB management, but the pathogenicity of these strains has not been reported (Corpoica 2013; García de León and Mier 2010; Williams et al. 2013). To our knowledge, this is the first report evaluating commercial strains of $B$. bassiana against this insect pest. Some studies have shown the virulence of entomopathogens and their potential as a control measurement for other beetle pests of the Curculionidae family in larva and adult stages (Bruck 2004; Shapiro-Ilan et al. 2004; Carrillo et al. 2015). These studies showed significant mortalities, compared to controls, in percentages starting at $40 \%$ for larvae (Bruck 2004) and 52\% for adults (Carrillo et al. 2015), by submerging individuals in spore solution. Our results showed higher pathogenicity of the commercial formulation of B. bassiana on ASB adults using direct inoculation method, with mortality values of $100 \%$ for all except the lowest concentration, which showed a mortality of $93 \%$, indicating a possible higher efficiency of this strain in pest control. These reports show the potential of entomopathogens as control agents
Fig. 1 Survival curves of ASB after direct inoculation with different spore concentrations of a commercial strain of $B$. bassiana (B.b-1). CC: commercial concentration $\left(2.5 \times 10^{8}\right.$ spores/ $\mathrm{mL}) . \mathrm{C} 2.5, \mathrm{C} 5, \mathrm{C} 7.5$ and $\mathrm{C} 10$ correspond to $2.5,5,7.5$ and 10 fold times CC, respectively. Survival curves calculated by Kaplan-Meier analysis.

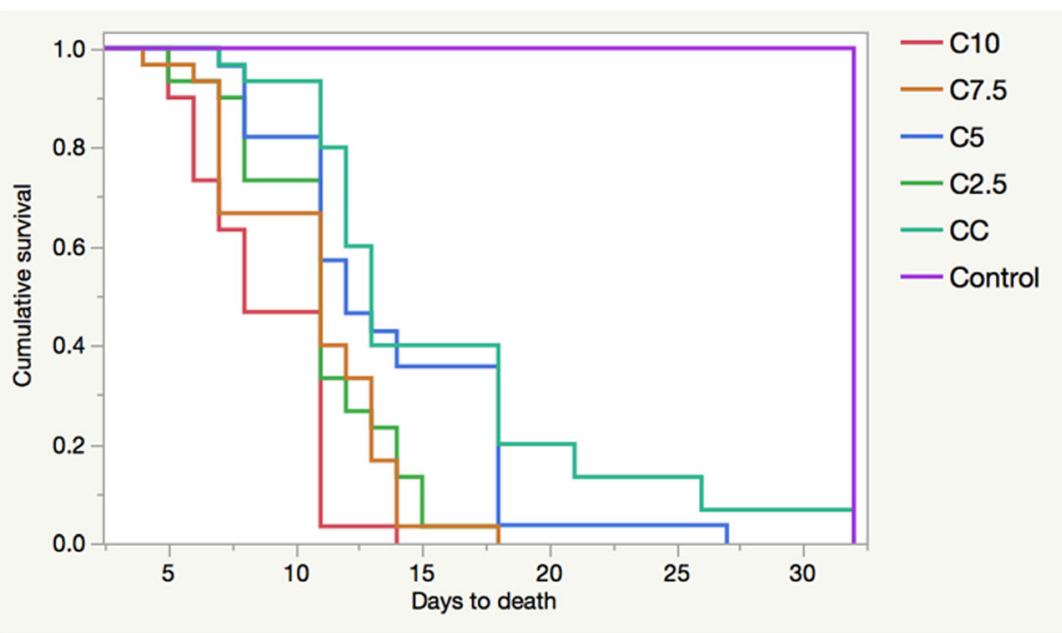




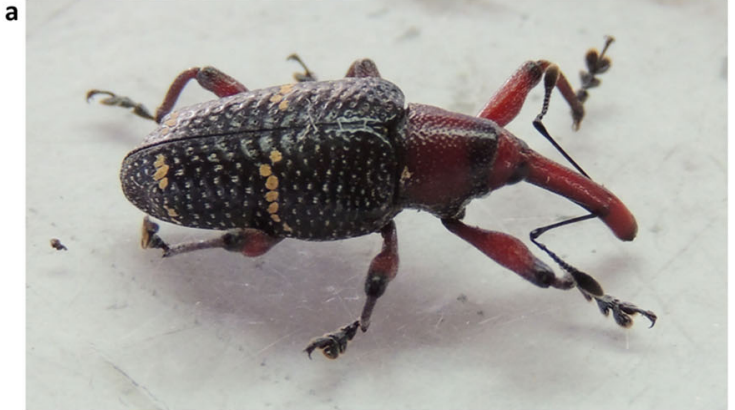

Fig. 2 Heilipus lauri (ASB) after inoculation with control solution or B. bassiana (B.b-1) spore solution. a Control H. lauri adult. b Dead $H$. lauri inoculated with $B . b-1$ after one week of incubation in humid

of ASB and could be used as baseline to support the search for native and more specific strains of entomopathogens for ASB.

Beauveria bassiana (B.b-1) caused a significant decline in the mean survival times of ASB adults, reaching mortality after 8 to 30 days, depending on the inoculation method and the spore concentration. This insect has a relatively long life cycle in which the adult stage can last up to 464 days (Castañeda 2008). On the other hand, ASB adults may feed on avocado sprouts, leaves, buds and fruits at different ripening stages (Caicedo et al. 2010). The decrease of ASB survival times after B.b-1 inoculation may suggest a decrease of damage to avocado trees due to a shorter exposure time to the pest. Future evaluations in the field will be necessary to test whether the application of $B$. bassiana can reduce ASB damage in avocado groves and before a recommendation is released to avocado farmers. Nonetheless, our results showed the potential of this $B$. bassiana strain to act as a biological control agent against ASB and the need for further tests of other $M$. anisopliae strains to confirm its low pathogenicity against this insect.

The negative effects of $B$. bassiana B.b-1 against ASB were more prominent on feeding parameters with the indirect inoculation (insects feeding on fruits immersed in spore solution). The evaluated $B$. bassiana strain not only caused a delay in the feeding initiation time (more than two days) but also decreased the intake amount during the assay. A reduction in the feed consumption and conversion of ingested food have been observed after infection with $B$. bassiana in other insects

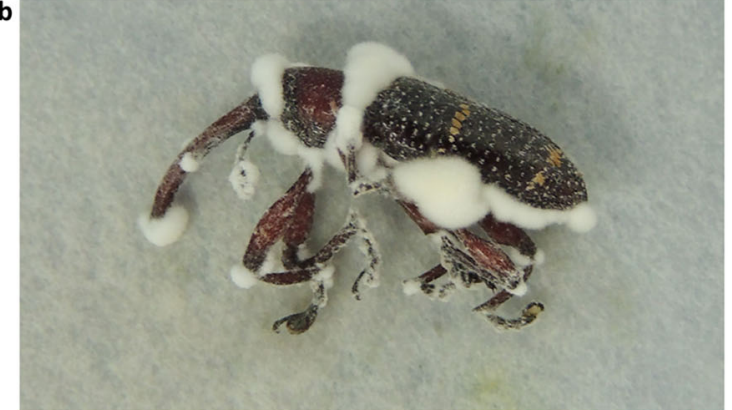

chambers at $25^{\circ} \mathrm{C}$. Final art work for this figure was created in Adobe Photoshop CC 2015.0.1 release.

such as Ocinara varians (Hussain et al. 2009), Spodoptera litura (Vinayaga Moorthi et al. 2015) or Chilo partellus (Tefera and Pringle 2003). These reductions were explained partly by the presence of toxins during the exposure with the entomopathogenic fungi or their secondary metabolites (Vinayaga Moorthi et al. 2015). The release of toxins by B.b-1 could explain the altered feeding behavior of ASB in indirect inoculation, as observed in Bemicia tabaci with crude toxins extract from Lecanicillium lecanii producing an antifeedant effect (Wang et al. 2007). However, further research should study the effect of $B$. bassiana toxins on ASB adults feeding behavior. Our results could imply a reduction in insect fitness, considering that ASB females oviposit into the perforations made on the fruit during the feeding (Caicedo et al. 2010). Additionally, the combined outcomes (lethal and sublethal effects) after treatment with B.b-1 could lead to an ASB population decline: for instance, the highest mortality was observed with direct inoculation after concentration C2.5 (6.25 $\times 10^{8}$ spores $\left./ \mathrm{mL}\right)$, which also showed negative effects on insect feeding in the indirect inoculation method.

To increase convenience for management recommendations the spore concentrations evaluated in this study were expressed in terms of the recommended commercial concentration. The $\mathrm{MLC}_{50}$ obtained for B.b-1 applied directly to the insect corresponded to a lower concentration than the recommended concentration, and $2.5 \times 10^{8}$ spores $/ \mathrm{mL}$ showed high virulence results. These two concentrations may possibly be used as a starting range for field evaluations to assure high and
Table 3 Median lethal concentration $\left(\mathrm{MLC}_{50}\right)$ of B.b-1 for ASB adults after direct and indirect inoculation

\begin{tabular}{llll}
\hline Inoculation & $\mathrm{MLC}_{50}$ (Fid. Lim. 95\%) & Probit equation & GOF Pr $>\chi^{2}(\mathrm{df})$ \\
\hline Direct & $1.40 \times 10^{8}\left(8.07 \times 10^{7}-1.89 \times 10^{8}\right)$ & $8.37 \times 10^{-8}+0.53(\mathrm{C})$ & $1.00(4)$ \\
Indirect & $2.29 \times 10^{9}\left(1.8710^{9}-3.11 \times 10^{9}\right)$ & $3.65 \times 10^{-6}+1148.6(\mathrm{C})$ & $0.101(4)$ \\
\hline
\end{tabular}

Parameter estimates for $\mathrm{MLC}_{50}(\mathrm{spore} / \mathrm{mL}$ ) includes the $95 \%$ fiducial limits (Fid. Lim.), the general response equation as function of spore concentration and, the $\chi^{2}$ Goodness of Fit test (GOF) p-values and degrees of freedom (df). The GOF determines if the distribution estimated with Probit analysis fits the empirical distribution $\left(P>0.05\right.$ fail to reject $\left.\mathrm{H}_{0}\right)$ 
a
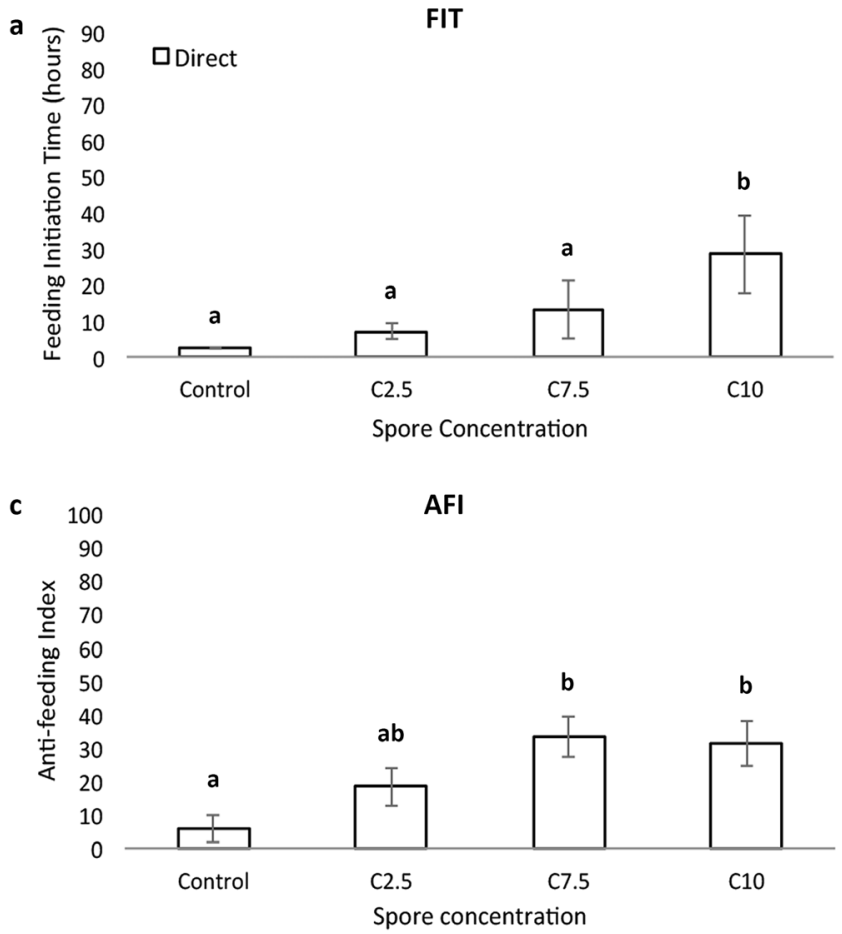

Fig. 3 Feeding initiation time (FIT) and Anti-feeding index (AFI) for ASB after direct and indirect inoculation with three spore concentrations of a commercial strain of B. bassiana (B.b-1). FIT: corresponds to the first feeding perforation occurred in the avocado fruit after inoculation. AFI: data from two areas of $3 \times 3 \mathrm{~cm}$ on the avocado fruit for each experimental unit. a FIT for direct inoculation; b FIT for

rapid mortality, as well as manifestation of sublethal effects, and might allow for a cost-effective recommendation to avocado farmers for ASB control.

Currently, none of the commercial entomopathogens in Colombia are registered for ASB control (ICA 2019). Due to the rapid increase of avocado production area in Colombia (AGRONET 2016) and the urgency for quarantine pest control, only currently registered commercial formulations were evaluated in this study. This could imply that, after field evaluations, avocado farmers in Colombia will be able to acquire the appropriate commercial formulations (produced under high standards) rapidly and use them as a sustainable alternative for ASB control. However, additional entomopathogens, such as M. anisopliae, Brevibacillus laterosporus, Xenorhabdus nematophilus, have shown a significant decrease in the feeding intake of other insects (Ruiu et al. 2006; YongLing et al. 2010; Ekesi 2011; Mohammadbeigi and Port 2015). To extend the alternatives for ASB control, other entomopathogens may be evaluated in the future for sublethal effects.

In conclusion, this study showed the susceptibility of ASB adults to a commercial strain of $B$. bassiana, by direct contact with a spore solution or indirectly through an infected surface. In comparison, a strain of $M$. anisopliae showed low pathogenicity against this insect. Additional field evaluations are needed to establish the effect of environmental and ecological
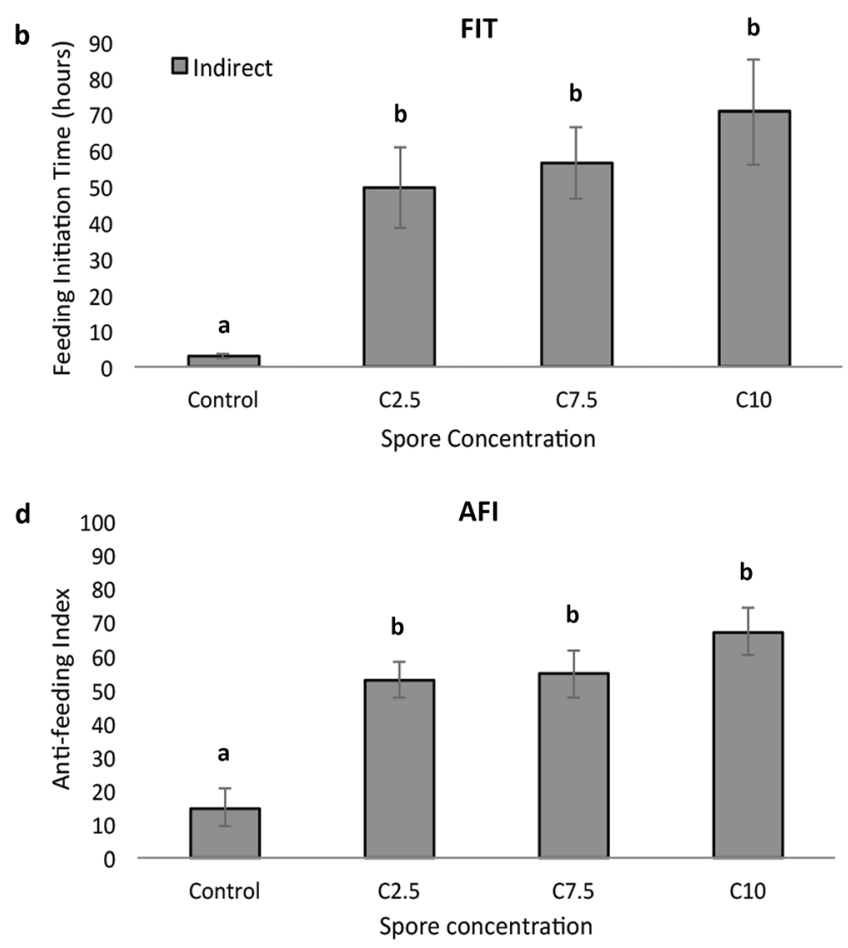

indirect inoculation; c AFI for direct inoculation; d AFI for indirect inoculation. Different letters correspond to significant different values within inoculation method $(P<0.05)$. Spore concentrations correspond to $2.5(\mathrm{C} 2.5), 7.5(\mathrm{C} 7.5)$ or $10(\mathrm{C} 10)$ times the recommended commercial concentration $\left(2.5 \times 10^{8}\right.$ spores $\left./ \mathrm{mL}\right)$.

conditions on the virulence of this strain, as well as identification of a cost-effective concentration. Moreover, a successful negative impact of $B$. bassiana on some sublethal effects was observed; however, other effects, such as oviposition, should be tested. Application methods and spore concentrations influenced B. bassiana pathogenicity and may also be considered for future evaluations. Finally, research on native ASB entomopathogens is required to improve control over this avocado quarantine pest.

Acknowledgements We thank the supporting personnel of Corporación Colombiana de Investigación Agropecuaria - AGROSAVIA, La Selva, Ovidio Montoya and Rosa Helen Mira for their help with the bioassays and a special thanks to Carlos Enrique Velazques for rearing the insects used in the bioassays.

Funding information This work was supported by the Sistema Nacional de Regalías (SGR) Antioquia, Colombia [Project 4,600,001,078 "Desarrollo tecnológico, productivo y comercial del aguacate en el departamento de Antioquia", 2012, adhesion contract number 1]. The funding source was not involved in the conduct of any part of the research or preparation of the manuscript.

\section{Compliance with ethical standards}

Conflict of interest The authors declare that they have no conflict of interest. 
Open Access This article is licensed under a Creative Commons Attribution 4.0 International License, which permits use, sharing, adaptation, distribution and reproduction in any medium or format, as long as you give appropriate credit to the original author(s) and the source, provide a link to the Creative Commons licence, and indicate if changes were made. The images or other third party material in this article are included in the article's Creative Commons licence, unless indicated otherwise in a credit line to the material. If material is not included in the article's Creative Commons licence and your intended use is not permitted by statutory regulation or exceeds the permitted use, you will need to obtain permission directly from the copyright holder. To view a copy of this licence, visit http://creativecommons.org/licenses/by/4.0/.

\section{References}

Abbott WS (1925) A method of computing the effectiveness of an insecticide. J Econ Entomol 18:265-267

Abrol DP, Shankar U (2012) Integrated pest management, principles and practice. CAB International, Cambridge, p 134

AGRONET (2016) Ministerio de Agricultura y Desarrollo Rural. www. agronet.gov.co. Accessed August 2019

Ambethgar V (2009) Potential of entomopathogenic fungi in insecticide resistance management (IRM): a review. J Biopestic 2:177-193

Barra P, Rosso L, Nesci A, Etcheverry M (2013) Isolation and identification of entomopathogenic fungi and their evaluation against Tribolium confusum, Sitophilus zeamais, and Rhyzopertha dominica in stored maize. J Pest Sci 86:217-226

Bruck DJ (2004) Natural occurrence of entomopathogens in Pacific northwest nursery soils and their virulence to the black vine weevil, Otiorhynchus sulcatus (F.) (Coleoptera: Curculionidae). Environ Entomol 33:1335-1343

Caicedo RL, Varón DE, Bacca T, Carabali A (2010) Daños ocasionados por el perforador del aguacate Heilipus lauri Boheman (Coleoptera: Curculionidae) en Tolima (Colombia). Rev Corpoica-Ciencia y Tecnol Agropecu 11:129-136

Carrillo D, Dunlap CA, Avery PB, Navarrete J, Duncan RE, Jackson MA, Behle RW, Cave RD, Crane J, Rooney AP, Peña JE (2015) Entomopathogenic fungi as biological control agents for the vector of the laurel wilt disease, the redbay ambrosia beetle, Xyleborus glabratus (Coleoptera: Curculionidae). Biol Control 81:44-50

Castañeda A (2008) Bioecología del barrenador grande de la semilla de aguacate Heilipus lauri Boheman (Coleoptera: Curculionidae) en la región central de México. Dissertation, Institución de Enseñanza e Investigación en Ciencias Agrícolas, Texcoco, Mexico

Corpoica (2013) Manual técnico actualización tecnología y buenas prácticas agricolas (BPA) en el cultivo de aguacate, Corpoica. Medellín, pp 226-233

Diaz V, Caicedo AM, Carabalí A (2017) Ciclo de vida y descripción morfológica de Heilipus Lauri Boheman (COLEOPTERA: CURCULIONIDAE) en Colombia. Acta Zool Mex 33:231-242

Ekesi S (2011) Pathogenicity and antifeedant activity of entomopathogenic hyphomycetes to the cowpea leaf beetle, Ootheca mutabilis Shalberg. Int J Trop Insect Sci 21:55-60

EPPO (1970) European and Mediterranean plant protection organization global database. EPPO Glob. Database https://gd.eppo.int/taxon/ HEILLA/distribution, Accessed August 2019

FAOSTAT (2016) Food and Agriculture Organization of the United Nations http://www.fao.org/faostat/en/\#home. Accessed Jan 2019

García de León S, Mier T (2010) Visión general de la producción y aplicación de bioplaguicidas en méxico. Soc Rural Prod Y Medio Ambient 10:37-63
Gilbert L, Gill S (2010) Insect control: biological and synthetic agents, First Ed. Elsevier, London pp 247, 396, 398

Gouli V, Gouli S, Marcelino J, Skinner M, Parker B (2013) Entomopathogenic fungi associated with exotic invasive insect pests in northeastern forests of the USA. Insects. 4:631-645

Hernandez L, Castañeda A, Urias-Lopez M, Fuentes LMH, Vildozola AC, Urías-López MA (2017) Weevil borers in tropical fruit crops: importance, biology and management. In: Shields Vonnie.D.C, E. (ed.), Insect Physiol Ecol. IntechOpen, Rijeka, pp 43

Hoddle M (2011) Biocontrol efforts against avocado pests in California: a review and recommendations for future proactive programs for identifiable invasion threats. Calif. Dep. Food Agric. https://www.cdfa. ca.gov/files/pdf/Avocado-invasives-biocontrol.pdf. Accessed Aug 2019

Hussain A, Tian MY, He YR, Ahmed S (2009) Entomopathogenic fungi disturbed the larval growth and feeding performance of Ocinara varians (Lepidoptera: Bombycidae) larvae. Insect Sci 16:511-517

ICA (2019) Productos registrados bioinsumos. Prod. Regist. Bioinsumos. https:/www.ica.gov.co/getdoc/2ad9e987-8f69-4358b8a9-e6ee6dcc8132/productos-bioinsumos-mayo-13-de-2008.aspx. Accessed Aug 2019

Kaplan EL, Meier P (1958) Nonparametric estimation from incomplete observations. J Am Stat Assoc 53:457-481

Lacey LA, Goettel MS (1995) Current developments in microbial control of insect pests and prospects for the early 21 st century. Entomophaga. 40:3-27

Lacey LA, Shapiro-ilan DL (2008) Microbial control of insect pests in temperate orchard systems : potential for incorporation into IPM. Annu Rev Entomol 53:121-144

McKenzie HL (1935) Biological control of avocado insects and mites bulletin 592. California Agricultural Experiment Station, Berkeley, p 40

Medina-Quiroz F, Loéz-Martinez V, Alia-Tejacal I, Garcia-Ramirez M, Guillen D, Andrade M, Villegas O, Acosta C (2010) Barrenador grande del hueso del aguacate (Heilipus lauri Boheman) en Tepoztlan. Morelos Investig Agropecu 7:67-75

Mohammadbeigi A, Port G (2015) Effect of infection by Beauveria bassiana and Metarhizium anisopliae on the feeding of Uvarovistia zebra. J Insect Sci 15:88-91

Pena JE (1998) Current and potential arthropod pests threatening tropical fruit crops in Florida. Proc Florida State Hortic Soc 111:339-340

Ruiu L, Delrio G, Ellar DJ, Floris I, Paglietti B, Rubino S, Satta A (2006) Lethal and sublethal effects of Brevibacillus laterosporus on the housefly (Musca domestica). Entomol Exp Appl 118:137-144

Sanchez-Bayo F, Goka K (2014) Pesticide residues and bees - a risk assessment. PLoS One 9(4):e94482. https://doi.org/10.1371/ journal.pone. 0094482

SAS-Institute-Inc (2004) The LIFETEST procedure. SAS/STAT User Guide Version 8. SAS Institute, Cary, pp 1797-1851

SENASICA-DGSV (2016) Barrenador grande de la semilla del aguacate, Heilipus lauri Boheman. (Coleoptera: Curculionidae). Fichas técnicas https://www.gob.mx/cms/uploads/attachment/file/155685/ Ficha_T_cnica_Helipus_lauri_EPF_2016_1_.pdf. Accessed Aug 2019

Shapiro-Ilan DI, Jackson M, Reilly CC, Hotchkiss MW (2004) Effects of combining an entomopathogenic fungi or bacterium with entomopathogenic nematodes on mortality of Curculio caryae (Coleoptera: Curculionidae). Biol Control 30:119-126

Singh RP, Pant NC (1980) Hymenocallis littoralis Salisb. as antifeedant to desert locust Schistocerca gregaria Forsk. Indian J Entomol 42: 460-464

Strasser H, Vey A, Butt T (2000) Are there any risks in using entomopathogenic fungi for pest control, with particular reference to the bioactive metabolites of Metarhizium Tolypocladium and Beauveria species. Biocontrol Sci Technol 10:717-735 
Tefera T, Pringle K (2003) Food consumption by Chilo partellus (Lepidoptera: Pyralidae) larvae infected with Beauveria bassiana and Metarhizium anisopliae and effects of feeding natural versus artificial diets on mortality and mycosis. J Invertebr Pathol 3(84): 220-225

USDA (2014) Miscellaneous and processed products import manual. USDA APHIS manuals. https://www.aphis.usda.gov/import export/plants/manuals/ports/downloads/miscellaneous.pdf. Accessed Jan 2019

Vinayaga Moorthi P, Balasubramanian C, Selvarani S (2015) Efficacy of sub lethal concentration of entomopathogenic fungi on the feeding and reproduction of Spodoptera litura. SpringerPlus 4:681

Wang L, Huang J, You M, Guan X, Liu B (2007) Toxicity and feeding deterrence of crude toxin extracts of Lecanicillium (Verticillium) lecanii (Hyphomycetes) against sweet potato whitefly, Bemisia tabaci (Homoptera: Aleyrodidae). Pest Manag Sci 63(4):381-387

Williams T, Arredondo-Bernal H, Rodriguez-del-Bosque L (2013) Biological pest control in Mexico. Annu Rev Entomol 58:119-140

Wolfenberger D, Colburn B (1966) Recent observations in some avocado pests in Mexico and El Salvador. Proc Florida State Hortic Soc 79: 335-337

YongLing J, RiChou H, Bin C (2010) Characteristics of insect antifeedants from entomopathogenic bacteria Xenorhabdus nematophilus strain all against Plutella xylostella. Chin J Biol Control 26:132-137

Publisher's note Springer Nature remains neutral with regard to jurisdictional claims in published maps and institutional affiliations. 